\title{
Content Knowledge is Important During those Early Years in a Student's Education
}

\author{
Barba Aldis Patton \\ University of Houston-Victoria, USA
}

\begin{abstract}
The content knowledge given to a young student in those early years is extremely important. Many of the misconceptions (presented as facts) to young students remain with them throughout their lives. These misconceptions of facts are often difficult to change as they seem to be ingrained in the students' minds. Misconceptions in mathematical operations was studied greatly in the 50s', 60's, and 70's. While educators seem to have moved their focus, we still need to be aware and able to guide students in a positive direction. Teachers absolutely must be able to teach in an academically appropriate way the students will learn math. Several examples of teacher's lack of content knowledge in both mathematics and science can and will harm students academically are provided. These examples will support why we need a highly qualified in content knowledge and skilled educator in every math classroom. The teacher of younger students is often thought of a babysitter, well that should not be the case. Teaching younger students must be more. These teachers must have high content knowledge in the discipline in order to prepare the student for future learning. Learning time is precious and students do not have the time to devote to un-learning misconceptions.
\end{abstract}

\section{Introduction}

There is an old adage that "those who can do and those who can't teach" which has been around for many years and may have been true at some point in time but with the presence of the standardize tests today, it is just an old adage. There is much more to teaching that just reading a book or telling students something. Teaching in not just something to do when you can't find a job. Just ask any successful teacher. Teachers today are expected to by filling or guiding students to expand their cognitive knowledge every second of their waking day. Teaching is a career which presents teachers with a new challenge or two every day. It is not an easy job. You don't get 'coffee breaks' in the morning and in the afternoon and you definitely do not get a two-hour lunch. You are lucky if you get a 2-minute bathroom break anything during the day and lunch is usually consumed while you are standing and observing students. [1] [2]

\section{Literature Review}

In this writing, this is a comparison of the content prepared teacher and the content unprepared teacher in the discipline of mathematics. This comparison will be made via several different viewpoints, such as review of literature, personal communications and surveys.

Today mathematics is one of the most important subjects for students to master and yet it seems to be the one to promote the most anxiety among the students. Students are bombarded by parents and other relatives who will say things like, "oh I could never do math so I guess you just inherited that too". "Math is just so difficult, one has to be a genius to understand it". "Math is easier for men as it is a man-thing". Then the students are often taught silly little mnemonics hoping to help them learn the rules of math when many times it would be easier to just learn the rules. But often these mnemonics are not for the general but only specific problems. [1], [2]

Students are expected to do fundamental problem solving daily. Problem solving is defined in this study as a mathematical situational problem which requires multi-steps to derive the answer. The days of just teaching basic computation are gone. Textbooks no longer have computation problems i.e. \#1-20 at the top of the page and then two or maybe three word problems at the bottom. In those classes of yesteryear, it was often heard students asking or begging to just do the odd numbers at the top and not do any of the word problems. The students often tried to bargain with the teacher almost anything if they could skip the bottom word problems. Teachers were no better than the students during this time frame, either. Teachers did not want to grade the word problems as they took much more time and they could not just do a quick check or ' $X$ '. Until Randall Charles [3] in the mid 80's took a stand and provided a method for grading word or stated problems, teachers were on their own. Many did not know how to evaluate except right answer or 
wrong answer. The 'Check or X' did allow the teacher to put a grade in the gradebook but it did nothing to help the students learn. Basically, it was a waste of time for both, teacher and student, Yes, the student did learn basic computation but did not gain any skills about learning to solve real life problems.

The work of Randall provided the teacher in the elementary grades with a rubric to grade those problems. It was no longer a guessing game of how to evaluate the student's work.

Another saying is "if you do not truly understand it, you cannot teach it". In this writing, both sayings will be examined. We are investigating the importance of teacher's content knowledge first in the teaching of mathematics.

In this work, we are using the definition of conceptual understanding of Hiebert and Lefevre [4],

Knowledge that is rich in relationships. It can

be thought of as a connected web of

knowledge, a network in which the linking

relationships are as prominent as the discrete

pieces of information. Relationships pervade

the individual facts and propositions so that

all pieces of information are linked to some network.

There are many reason why teachers do not have the content knowledge to be a strong teacher. In this study, we will not attempt to find or state reasons.

First, we know that new teacher is going into the classroom and we are going to presume she will do the best possible under the circumstances. The teacher is not out to deceive student however, the fact that she is the teacher of record gives the students the indication that she has conceptional knowledge of the subject. Unfortunately, the deception will not last very long even with the youngest of students. Cole (personal communication) was often heard telling his elementary teacher candidates, the PHD.s need to teach kindergarten and first grade, and the weak math teacher need to teach at the secondary level. He strongly believed the more advanced students would be able to master the math with or without an instructor, but the young students needed guidance from someone who truly understood the concepts and not just how to work specific problems. [5]. When teachers have the content knowledge, they will not be giving students so called 'tricks' which work on the problems today but will not work on problems tomorrow. Teachers with the content knowledge will only give students the generalizable algorithms for the students to be able to solve other situations. On the other hand, students are quick to pick up on a 'math trick' that will work for problem 1 but will not be the solution for all problems and this is what happens much of the time with a teacher of limited content knowledge.

\section{Explanations}

The teacher with limited content knowledge unknowingly gives rise to many misconceptions. One situation is when a teacher is introducing the students to area and perimeter. The area of a square is length of side squared or side times side. If the teacher has a square with length of 4 units on each side as an example. The teacher and the students quickly determine that the area of the square is 16 square units [6].

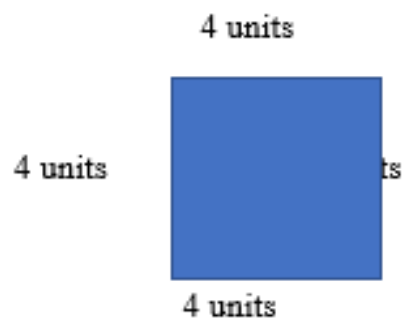

$$
\begin{aligned}
& A=s^{2} \\
& =4 \text { units }^{2} \\
& =4 \text { units } \mathrm{X} 4 \text { units } \\
& A=16 \text { sq. units } \\
& \mathrm{P}=4 \mathrm{X} \text { side } \\
& =4 \mathrm{X} 4 \text { units } \\
& P=16 \text { units }
\end{aligned}
$$

If the teacher continues with the lesson and is going to introduce perimeter of a square. He/She may do either of two ways. 1) to determine the perimeter, you simply add the length of the sides therefore $4+4+4+4$ $=16$ units. 2) since the figure is all four sides are equal, therefore you can just multiply 4 (sides) $\mathrm{X} 4$ units (length of side) $=16$ units. True area is 16 square units and perimeter is 16 units, but students at this learning stage are focusing on getting a number and are not looking at the units. As a result, many students when faced with different sized squares will compute just one, area or perimeter, and put the same figure in for both measurements. This can be a major stumbling block for the students in a classroom being guided by a teacher with very little content knowledge. It is best to use an example of a square of different length sides, such as 3 or even 5 units. The teachers with little content knowledge most likely will not be one to use manipulates and will only read and teach directly from the text book. The teacher with greater content knowledge might also have square tiles to be used as manipulatives for the students to move around and experience the different amounts. A misconception in this situation is many students will believe that the area and perimeter have an equal number. Some will go as far as telling an observer the only difference is the area has square units and the perimeter does not.

Misconceptions in math has been around most likely as long as people have engaged in any type of work in a mathematical sense. People in general are quick to jump to a conclusion that a rule, formula, etc. 
will work in all cases when it is only true for special one. An example is a formula to generate all the prime numbers. Many have been found but most have a flaw that it also generates multiples of the constant used in the formula.

Researchers in the area have offered as reasons for some of the error as 1) faulty rules interrupted in different context (such as when you multiply you always get a larger number... true if you are multiplying whole numbers but not true if you are multiplying fractions. 2) errors resulting from organized strategies (memorized algorithms and little crazy jingles) and lastly 3 ) students are brought up to believe that math is only used in isolated circumstances.

When young students are being taught addition, often they are told if you add

$$
2+4=6 \text { and } 4+2=6
$$

While this is true in addition, many young students take the rule to be applied to all situations. This is further strengthened when the student is learning multipion, but it isn't true for subtraction and division. However, many students will apply this property to all math situations.

As many young students are introduced to the concept of subtraction, they are told to just take the little number from the big one. Many teachers who lack content knowledge fail to tell and or show the students when and where it is appropriate. Yes, the rule is true for example $\mathrm{A}$, however it is not true for Example B. It seems the student just remembers 'you take the little number from the big one' It is most likely a problem that the limited content knowledge teacher.

Example A
36
$\frac{-12}{24}$
In the above problem
Subtracting the smaller number
is correct.

This seems like such a simply thing to help young math students learn how to subtract but we see when taken out of context it creates a problem for the student as he/she progresses in their math studies [8]. Another problem can be position. We all know that you start to do subtractions problems on the right but young students often can't remember right and left.

\section{Example B}

41

$\underline{-15}$

34

In this problem, subtracting the smaller

is not correct. This is a problem many

Young student encounter.

It is documented in the studies at the Shell Centre in the UK that a young student was able to do subtraction problems without any difficulties however, when she was promoted to the next grade and moved to a different classroom, she was not successful anylonger. Finally, after numerous attempts to recify the the situation, the child was interviewed. According to the interview, she didn't have a piano in the classroom so she did not know which side to start when solving the problem. It seems in the previous grade the teacher told her to always start on the side with the piano as there was one in that classroom. While this may have seemed to be a smart thing to do at time, if the teacher would have used some content knowledge this would not have been a problem. The teacher needed to provide the student with something that is and will be true yesterday, today and tomorrow [8].

Fraction and decimals are difficult for many students as they just do not understand that one can have a part of a number. A part of a cookie, pizza or other food is like a different language to them. To make understanding even more difficult, one can have one or more wholes and then a portion of another.

Another area of concern is when working with zero. Although it is often a place holder it is just that and can't be ignored. For example 105 is one hundred plus no tens and five ones (units). When teachers with limited content knowledge encourge young students to just say that 105 is one hundred five, they are not recogniziong that tens place in the number. This will lead to the student not being able to recognize the value of each and will also create problems if the student is to write the number is expanded notation.

$$
\begin{aligned}
105 & =100+00+5 \\
& =\left(1 \times 10^{2}\right)+\left(0 \times 10^{1}\right)+\left(5 \times 10^{0}\right)
\end{aligned}
$$

Most likely if the student had been taught by a teacher with limited content knowledge, they would take the short cut and not included the $\left(0 \times 10^{1}\right)$. By 
not including that step the student is highly likely to not have the exponents correct. The math teacher must truly understand place value or the student will have many difficulties. Since using numbers raised to the zero power is math beyond the content knowledge of many teachers, it will be easier to skip and avoid questions from the students thus showing that void. But who will suffer is the student when trying to do math in higher grades.

Fractions and decimals are other confusing concepts. Many teachers just do not grasp fractional parts greater than one or how to change a fraction to a decimal or back. As long as it is sharing cookies or pizza slices the teaching progresses along but when we get to other parts it is like a different language to them. To make understanding even more difficult, one can have one or more wholes and then a portion of another.

The sceniero often used is that of the cowboy and the horse. This is to help the student learn to convert a fraction to a decimal. We will use the fraction of $\frac{3}{5}$ to illustrate the story. Everyone knows a cowboy rides the horse and the horse does not ride the cowboy. The fraction is like a cowboy and his horse. The numerator (top number ) is the cowboy and the denomator (bottom number) is the horse.

Everyone know after a long day of riding when the cowboy comes home, he goes in the house and the horse stays out doors

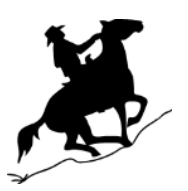

The cowboy rides his horse all day.

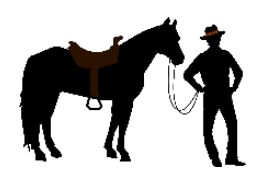

The two finally come home.

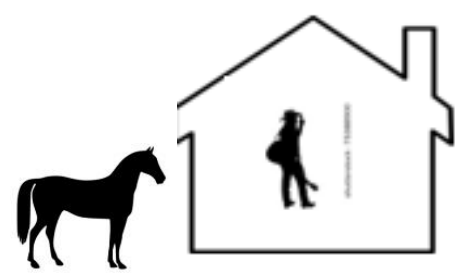

The cowboy unsaddles his horse and feeds him. Horse stays outside and the cowboy goes in the house to rest and eat.

Now we use this story to change a fraction to a demial.

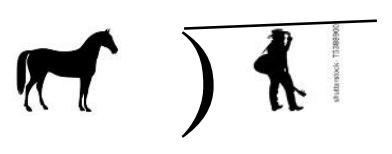

With that we now have

$5 \longdiv { 3 }$

\section{horse $\overline{\text { cowboy's house }}$}

This little story may seem to work if it is a proper fraction being changed to a decimal however, when it is an improper fraction (greater than one), students seem to get mixed up as to who/what is the cowboy and horse. (There are many cowboy and horse methods to change fractions to decimals, however none has ever shown much promise as a true method to teaching understanding). While other teachers who do not have the content knowledge will tell the young students to put the bigger number in the inside (meaning the radical sign) and the little number on the outside. There is no mention of such mathematics terms as numerator and/or denomator. What happens when the student reaches a higher grade level an the instructor uses proper mathematical terms and not the little cutey terms? Now the poor student is trying to remember if the cowboy is a numerator or demonator and what is the house? So many teachers who lack the content knowledge try to rely on tricks to teach is becomes scary. One of the problems also is the teachers are often facing high stakes testing. Therefore the teachers are worried about the moment and not preparing the students for future years. The teacher is just trying to have the students past the test while in their grade and classroom. Unfortunately, the stakes are so high for the teacher, he/she doesn't care or can't afford to care what happens the following year or beyond that.

To someone with content knowledge, it seems it would be easier to just use the proper terms and do the needed operations. The manner in which this is illustrated almost seems it is for a special needs classroom. However, it is not sure if it is the students who are special needs or the teacher who had the needs. If we move to try to illustrate on a number (track line) line, we have greater confusion.

Many mathematics teachers try to teach students to test for reasonability and this is a good method for many students. But for the ones who have been 
plagued with rounding misconceptions this can quickly turn into a disaster. An example is when a student is asked to round a large number such as 125486 to the nearest thousand. One method has the students to start with the smallest place value then move to the next greater until the number has been rounded to the desired place value.

Correct method
We know that 125,486 is closer to 125,000 or
126,000
What we know:
$125,486-125,000=486$
$126,000-125,486=514$
From these two facts, we can clearly see that
125,486 is closer to 125,000 than to 126,000

While the method starting with the simple and moving to the move complex seems to be an easier way, it is a method which will not pass a test for generalizability.

Misconceptions are in all disciplines, not just in mathematics. Science teachers find students coming to class with the idea that mass and weight are the same. Well, the result might be the same but not all the time at all places. As an example let's talk about our own weight and mass. On Earth and in space (Moon), we occupy the same amount of space as our mass is the same. Our clothing will fit the same on Earth as it does on the Moon. A person does not need a size 0 jumpsuit on the Moon but a size 10 on Earth. The jumpsuit size will be the same for both locations. Now comes the different, if a person weights $1200 \mathrm{~N}$ on Earth, he will only weigh $200 \mathrm{~N}$ on the Moon. This is because the mass of the Earth and the Moon are not of equal thus the gravitiy of the two differ also.

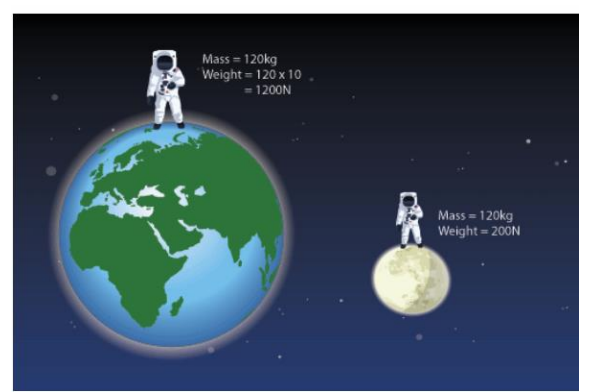

(retrieved July 30, 2017 from

http://www.bbc.co.uk/bitesize/ks3/science/energy_electrici ty_forces/forces/revision/3/)

Another example of incorrect information is when students are taught in the lower grades about items which will sink and which will float. This is often one of the first activities students do when they come to school for the first time. Students love to play in water and it is a great way to motivate them in learning. The students quickly see that paper clips, tacks and push

\section{Incorrect method}

First the student will round 125,486 to the nearest $10,100, \ldots$

125,486 to the nearest 10 will be 125,490

125,490 to the nearest 100 will be 125,500

125,500 to the nearest 1000 will be 126,000

But is 125486 actually closer to 126,000 or 125,000 ?

pins do not float. The students then make the assumption that all metal will not float. But what about the huge ocean liners?
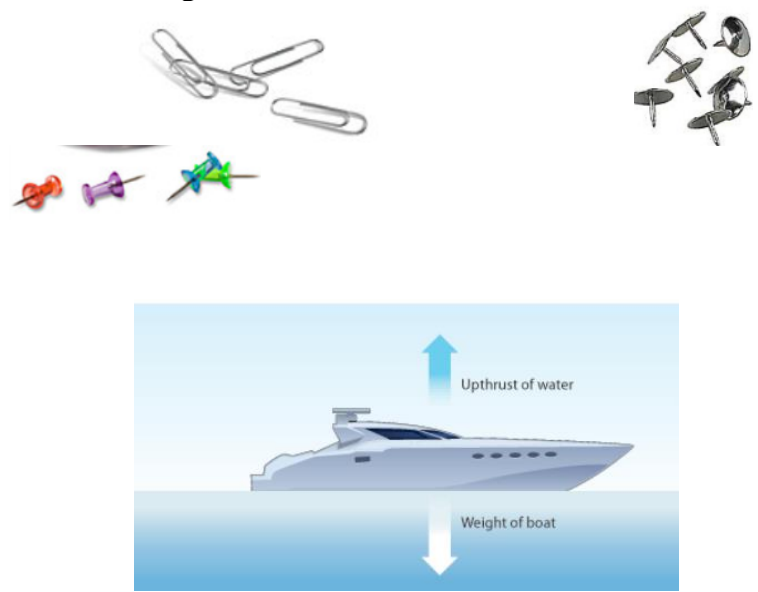

(retrieved July 30, 2017 from

http://www.bbc.co.uk/bitesize/ks3/science/energy_electrici ty_forces/forces/revision/5/)

They are made of metal. However, it is often taught without full explanations. Unfortunately, many times the explanations are missing as the teacher does not have the content knowledge to do so.

The list is almost endless. Teachers with limited content knowledge do not need to be in the classroom. This limited content knowledge can and will result in the students developing misconceptions. It seems to be common knowledge that once something right or wrong is rooted in one's memory, it is difficult to erase or remove. One such example is the pronunciation of a word. If a child's parent mispronounces the word and the child is exposed to that word several times, most likely that child will also mispronounce the word also. This seems to be engraved in the child's memory bank forever and even when the person is up in years, he/she will still pronounce that work incorrectly [8]. The word athlete often gets an ' $a$ ' added as a middle sound, espresso has an ' $x$ ' in place of the first ' $s$ ', a chest of drawers is called a 'chester drawers', film is called 'fillum', picture is very often pronounced pitcher which is a totally different word (picture is a copy of something you hang on the wall where a pitcher is either a member of a baseball team or a vessel for you to use 
to pour and the list is very close to being infinite. In addition, if a child's parent or other relative does not use standard English or has an accent then other word may appear.

Unfortunately, some of these are in the child's belief system and are resistant to change through traditional instruction. Teachers with limited content knowledge most likely will only have the methods suggested in the teacher's manual. When the teacher has a limited content knowledge, he/she will not have a repertoire of many different methods approaches to help erase the misconception. Simply repeating a lesson or trying to make it clearer is not the answer according to research. As difficult as it seems to believe, some teachers even think it they speak at a higher volume it will help the student to grasp the concept. Students are basing their reasoning on strongly held misconceptions. This reasoning is often strongly ingrained in their minds and is resistant to change. Many educators have documented in their studies that misconceptions truly create problems for students. Middle school teachers report on a frequent basis they are faced with trying to undo little 'cute' sayings the lower grade teachers had students say to complete tasks [9a].

As part of a recent survey conducted by Patton and Woods in 2017, students reported they had little to no faith in the accuracy of teachers who they felt did not know the content. The students were reflecting on some of the teacher they had personally encountered during their own education. These students reported that most of the time it was a wasted year in that class. They stated this was especially true if the instructor was a coach who was placed in a core area which was not his/her discipline. Students reported in the math classes, the assigned problems were either right or wrong according to the back of the book and there was never any explanation [9].

In this same study students reported they learned much more with the teacher who knew the content. They liked the teachers who would work problems with them an explain the process step by step rather than answer only. The students did not like teachers who came into to class with all the problems worked on a sheet of paper and then just copied to be visible for the students.

There is an endless list of misconceptions students face in their studies of math. Some are due to the young students trying to do some tricks to make homework go faster however many are due to the teacher having the lack of content knowledge. Unfortunately some math programs on the market have flaws and were not properly reviewed or were self-published. School districts and parents are at a disadvanteage with these. As consumers we believe that if something is on the market, it has be tested and is safe and good for all [10].

\section{Discussion}

As we have discussed a few of the misconceptions some are believed to be the result of teachers having limited or very little content knowledge. However we must also examine some of the myths which teachers are reminded each day. Some of the myths may be due the the more experienced teachers just not wanting to memtor the young educator and then some may not be able to help as they have a very limited content knowledge too.

If the young teachers have only the limited content knowledge, using the myths is more likely a way to try to justify the lack of knowledge while providing a reason to not try, If a young teacher is having diffiuclties teaching a concept, her peers at the grade level meetings may try to make her feel better by saying something such as, "Some people have a math mind and some don't". this myth might make her feel a litle better emotionally but does little to nothing to help her with her teaching problem. On another day, the teach might be seeking help with a student who is rather slow but progress in the class. He is having difficulties learning how to multiply. Rather than offer some suggestions for her to try and help the student, the peers might say something such as "math requires a good memory" but not offer any ideas or suggestions to help teach the students.

Teachers are the backbone of any education system, as they provide the pulse in the successful implementation of any educational program. However, when we look at the teacher content knowledge vises their teaching abilities (methods, ability to explain for understanding) it almost comes to be another old adage "What came first the chicken or the egg". Just take a moment to think, if the teacher does not have the content knowledge and teacher knowledge what do the students receive? A friendly face and friend. But that is not the mission of a student's schooling. Are students being educationed for live long learning and to be successful members of society? On the flip side, the teacher who knows teaching strageties but does not have mathematics knowledge, could be a negative determental in an early classroom. That teacher might be teaching rules, algorimthms which are incorrect for mathentics in a specific case or time. Fractions is a concept that many teachers seem to find cute little stories, etc to make it easier for the students for a specific time but then when the students moves forward to more complex math concepts these litte cute stories not longer work and the student becomes flustrated and no longer wants to even think about math.

It seems to come to the fact, yes we need a highly qualified teacher in the classroom. Today's highly qualified teacher is one who has the content knowledge and the pedigocal skills to teach students. This highly qualified person absolutely must have the content knowledge and not be using trickery to solve 
the specific problems but be able to guide students to be able to solve all in that concept.

After carefully researching the misconceptions students have in just the mathematics discipline** if the teacher is not qualified, don't you want a a teacher who can and does to be the teacher for your child? A successful teacher today, is one who can (knows the content) and does (teach the discipline.

\section{References}

[1] Barlow, A T. \& Reddish, J. M. (2006) Mathematical myths: Teacher candidates' beliefs and the implications for teacher education The Teacher Educator. 41(3 145-157.

[2] West. S.S. \& Browning S. T. (2011) Confusing language for science and mathematics students. The Texas Science teacher.

[3] Charles, R. I. (1983). Evaluation and problem solving. Arithmetic Teacher, 306

[4] Hiebert, J., \& Lefebvre, P. (1986). Conceptual and procedural knowledge in mathematics: An introductory analysis. In J. Hiebert (Ed.), Conceptual and procedural knowledge: the case of mathematics (pp. 1-27). Hillsdale, NJ: L. Erlbaum Associates.

[5] Ginsberg, H. (1977). Children's arithmetic: How they learn it and how you teach it. Austin, TX: Pro-Ed.

[6] Patton, B. A. (2016) Webster, where are you? Vocabulary confusion on state tests. (in review).

[7] Ashlock, R. B. (2010) Error patterns in computation: Using error patterns to help each student learn $\left(10^{\text {th }} \mathrm{Ed}\right.$.) Merrill Education/Prentice Hall. Upper Saddle River, NJ ISBN13: 978-0135009109.

[8] Patton, B. A. (1992) Error patterns in the interpretation of line graphs. Unpublished dissertation.

[9] Patton, B. A. \& Woods, K. B, (in progress) Student's perceptions of teachers' ability to teach.

[10] West, Ada (nd) Misconceptions and errors. Retrieved July 15, 2017. https://www.westada.org/cms/lib/ ID01904074/.../Misconceptions_Error\%202.pdf 